Check for updates

Cite this: J. Mater. Chem. B, 2020, 8, 1049

Received 10th November 2019 Accepted 2nd January 2020

DOI: 10.1039/c9tb02537e

rsc.li/materials-b

\section{Polypropylene mesh for hernia repair with controllable cell adhesion/de-adhesion properties $\dagger$}

\author{
Sonia Lanzalaco, (D) *ab Luis Javier Del Valle, (D) ab Pau Turon, (D) ${ }^{\text {ac }}$ Christine Weis, ${ }^{\text {ac }}$ \\ Francesc Estrany, ${ }^{\mathrm{ab}}$ Carlos Alemán (D) ${ }^{\mathrm{ab}}$ and Elaine Armelin (D) *ab
}

\begin{abstract}
Herein, a versatile bilayer system, composed by a polypropylene (PP) mesh and a covalently bonded poly( $N$-isopropylacrylamide) (PNIPAAm) hydrogel, is reported. The cell adhesion mechanism was successfully modulated by controlling the architecture of the hydrogel in terms of duration of PNIPAAm grafting time, crosslinker content, and temperature of material exposure in PBS solutions (below and above the LCST of PNIPAAm). The best in vitro results with fibroblast (COS-1) and epithelial (MCF-7) cells was obtained with a mesh modified with a porous iPP-g-PNIPAAm bilayer system, prepared via PNIPAAm grafting for $2 \mathrm{~h}$ at the lowest $N, N^{\prime}$-methylene bis(acrylamide) (MBA) concentration (1 mM). Under these conditions, the detachment of the fibroblast-like cells was $50 \%$ lower than that of the control, after 7 days of cell incubation, which represents a high de-adhesion of cells in a short period. Moreover, the whole system showed excellent stability in dry or wet media, proving that the thermosensitive hydrogel was well adhered to the polymer surface, after PP fibre activation by cold plasma. This study provides new insights on the development of anti-adherent meshes for abdominal hernia repair.
\end{abstract}

\section{Introduction}

Abdominal wall hernia is the result of abdominal wall muscle or connective tissue weakness that allows visceral organs to herniate through. ${ }^{1}$ Several prosthetic biomaterial-based devices for hernia repair are commercially available, while more innovative and clinically efficient ones are under investigation. ${ }^{1}$ Among them, polypropylene (PP)-based fabrics are largely employed and PP meshes have been accepted for a long time as a standard element for abdominal hernia repair. ${ }^{2}$ These meshes are pliable, well incorporable into adjacent tissues and capable of giving robust mechanical support. ${ }^{3}$

Nevertheless, little flexibility, adhesion to visceral organs and inflammatory risks are problems connected with the utilization of these materials. ${ }^{4}$ The employment of light-/mid-weight PP meshes characterized by low density and low stiffness of the polymer is one strategy currently used to reduce these complications. ${ }^{5}$

\footnotetext{
${ }^{a}$ Departament d'Enginyeria Quimica, EEBE, Universitat Politècnica de Catalunya, C/Eduard Maristany, 10-14, Ed. I.2, Barcelona, 08019, Spain.

E-mail: sonia.lanzalaco@upc.edu, elaine.armelin@upc.edu

${ }^{b}$ Barcelona Research Center for Multiscale Science and Engineering, Universitat Politècnica de Catalunya, C/Eduard Maristany, 10-14, Ed. I.S, Barcelona, 08019, Spain

${ }^{c}$ Research and Development, B. Braun Surgical, S.A. Carretera de Terrassa 121, 08191 Rubi (Barcelona), Spain

$\dagger$ Electronic supplementary information (ESI) available. See DOI: 10.1039/c9tb02537e
}

However, the reduction of the weight of the material is limited by the need to guarantee the minimum strength required to support the tissue, as well as an adequate stiffness for easy handling by the surgeons, particularly during intra-operative placement and fixation. Another drawback, crucial for the patient, is the risk of adhesion, especially to organs, that presents an incidence rate as high as $80 \%$ and could lead to serious problems like obstruction of the bowel and infertility in female patients, beyond chronic pain. ${ }^{6}$ Recurrent surgery is needed in those cases with complications and high health care costs are expected. Prompted by these requirements, an increasing number of surgical mesh materials, including non-adherent polymer meshes, composite polymer meshes, and meshes made using various naturally occurring biomaterials, have been developed. ${ }^{7-10}$ Considering the burden related to diseases that need surgery and the need to minimize the frequency of reoperations, a pressing need to provide an improved standard of innovative and, at the same time, not prohibitively expensive surgical care is of great interest to the research community and manufacturers.

In a previous study, ${ }^{11}$ we successfully prepared a novel surgical mesh, composed by a commercial light-weight PP substrate and a thermoresponsive hydrogel, poly( $N$-isopropylacrylamide- $c o-N, N^{\prime}$ methylene bis(acrylamide) (PNIPAAm-co-MBA). ${ }^{12}$ The new hardsoft bilayer system was designed to reduce the problems of organ adhesion, discussed above, after mesh implantation. In particular, the hydrogel microstructure resembles natural tissue and due to its 
stimuli responsive properties, it has been reported to be applied for various biomedical purposes, such as smart actuators for chemical valves, ${ }^{13}$ scaffolds for tissue engineering, ${ }^{14,15}$ "on/off" switches for chemical reactions, ${ }^{16,17}$ vehicles for drug delivery, ${ }^{14,18}$ matrices for bioseparations, ${ }^{15,19}$ and "artificial" muscles and soft biomimetic machines. ${ }^{20-22}$ Among the stimuli-responsive hydrogels, temperature-responsive PNIPAAm is the most attractive, because the temperature variation is easily controlled by an external stimulus.

Several kinds of temperature-responsive hydrogels with responsive-bending properties have been recently developed. ${ }^{23,24}$ In some advanced applications such as temperature-controlled "soft robots", the bending response to temperature is crucial. Moreover, the utilization of these materials in devices for biomedical applications also demands good biocompatibility with the surrounding tissue. ${ }^{25}$ Specifically, the lower critical solution temperature (LCST) of PNIPAAm, which occurs within the range of $32-33{ }^{\circ} \mathrm{C}$, is attractive for a variety of biological applications. ${ }^{12,26}$ Upon heating above the LCST, the hydrogel evolves from a hydrophilic to a hydrophobic state, resulting in a drastic change in the hydrogel volume caused by water expulsion. ${ }^{26}$ In some cases, hydrogels were loaded with functional nanomaterials. For example, Yamamoto et $a .^{27}$ developed an optically responsive flexible/stretchable actuator that wraps around a human wrist or a finger after heating. The thermosensitive part of that flexible actuator, which was stimulated by the temperature of the human body and sunlight without any artificial power source, was composed of PNIPAAm and carbon nanotubes (CNTs).

On the other hand, the biocompatibility of the PNIPAAm hydrogel has been widely demonstrated ${ }^{12}$ and, additionally, some authors investigated the ability of PNIPAAm to control cell adhesion. ${ }^{19,28-31}$ For example, Okano et al. ${ }^{19}$ reported that the PNIPAAm-grafted solid surfaces have an inherent hydrophilic-hydrophobic switch induced by temperature variation, which was used to control the detachment of the cultured cells. Nowadays, scientific interest has moved towards more complex substrates, with 2D and 3D-geometries, like gel fibres, cell sheets, and patterned substrates. ${ }^{32-35}$

In this work, we focus on the modulation of the cell adhesion and the cell proliferation in a bilayer platform, composed of a PNIPAAm-grafted PP mesh with 2D-geometry. Then, the influence of the concentration of the crosslinker (MBA) and polymerization time on the properties of the new system, including copolymer composition and morphology architecture, have been explored.

The novelty here is the elucidation of the mechanism responsible for such cell-adhesion and de-adhesion when the PNIPAAm-co-MBA monolayer film (adherent on one hand to the PP substrate and anti-adherent on the other hand to cell proliferation) is being employed.

\section{Experimental section}

\subsection{Materials}

Lightweight monofilament Optilene ${ }^{\circledR}$ Mesh LP was used as a substrate for grafting reactions (B. Braun Surgical, S.A.).
Optilene ${ }^{\circledR}$ Mesh LP is a flexible and non-absorbable isotactic PP (iPP) mesh, with $36 \mathrm{~g} \mathrm{~cm}^{-2}$ weight per area, $1.0 \mathrm{~mm}$ pore size and $0.39 \mathrm{~mm}$ thickness. $N$-Isopropylacrylamide (NIPAAm) monomer (purity 99\%, CAS 2210-25-5), N, $N^{\prime}$-methylene bis(acrylamide) (MBA) crosslinker (Reagent Plus 99\%, CAS 110-26-9) and $N, N, N^{\prime}, N^{\prime}$-tetramethylethylenediamine initiator (TEMED, Reagent Plus 99\%, CAS110-18-9) were supplied by Sigma-Aldrich (Spain). Ammonium persulfate catalyst (APS, purity 98\% CAS772754-0) was provided by Panreac S.A. All reagents were used as received. Milli-Q water grade $\left(0.055 \mathrm{~S} \mathrm{~cm}^{-1}\right)$ was used in all synthetic processes. Nitrogen gas was used for the radical polymerization reactions and was of pure grade (99.995\% purity).

For cell culture experiments, adherent cells derived from soft tissue, such as epithelial-like (MCF-7), derived from human adenocarcinoma of mammary gland, and fibroblast-like (COS-1), derived from African green monkey kidney) cells, were selected and purchased from ATCC (USA). Dulbecco's phosphate buffered saline (PBS) solution without calcium chloride and magnesium chloride, Dulbecco's modified Eagle's medium (DMEM, with $4500 \mathrm{mg} \mathrm{L}^{-1}$ glucose, $110 \mathrm{mg} \mathrm{L}^{-1}$ sodium pyruvate and $2 \mathrm{mM}$ L-glutamine), penicillin-streptomycin, 3-(4,5-dimethylthiazol-2yl)2,5-diphenyltetrazolium bromide (MTT, 97.5\%) and trypsin EDTA solution $(0.05 \%$ trypsin, $0.02 \%$ EDTA) were purchased from Sigma-Aldrich (USA). Fetal bovine serum (FBS) and trypan blue stain $(0.4 \%)$ were purchased from Gibco (UK).

\subsection{Preparation of the PP mesh grafted with PNIPAAm-co-MBA bioactive platform (iPP- $g$-PNIPAAm)}

The pristine Optilene ${ }^{\circledR}$ Mesh LP was first activated with oxygen plasma (plasma power $250 \mathrm{~W}$, purging pressure of $0.07 \mathrm{mbar}$, gas flow fixed for $180 \mathrm{~s}$ and $20 \mathrm{sccm}) .{ }^{11}$ After plasma treatment, all samples were stored under vacuum for a few days, if not used immediately for the deposition of the soft hydrogel PNIPAAm.

The graft copolymerization of the NIPAAm monomer onto the iPP meshes was carried out by adapting a procedure described in the literature. ${ }^{36}$ Briefly, NIPAAm monomer (0.5658 g, $250 \mathrm{mM}$ ), and TEMED catalyst $(0.0065 \mathrm{~g}, 2.77 \mathrm{mM}$ ) were dissolved in $20 \mathrm{~mL}$ of water in a reaction vessel. The amount of MBA cross-linker was varied (i.e. 1, 2 and $4 \mathrm{mM}$ ). After total dissolution, all reagents were mixed with a pre-weighed Optilene ${ }^{\circledR}$ mesh LP $\left(4 \mathrm{~cm}^{2}\right)$ in the same reaction vessel. The solution was stirred under nitrogen gas flow (30 $\mathrm{min}$ ) to remove the dissolved oxygen, before the addition of the initiator. Then, $0.15 \mathrm{~mL}$ of APS $(370 \mathrm{mM})$ aqueous solution was added to the vessel to initiate the polymerization. The temperature was maintained at $30{ }^{\circ} \mathrm{C}$ with water bath. Different reaction times were tested (i.e. 1, 2, 4 and 20 h). Afterwards, samples composed by a bilayer of the PNIPAAm- $c o$-MBA hydrogel, which were well adhered to the monofilament mesh, were extracted and poured onto $400 \mathrm{~mL}$ of Milli-Q water. They were maintained under stirring for $4 \mathrm{~h}$ for purification by continuous replacement of Milli-Q water. All iPP- $g$-PNIPAAm/MBA systems (hereafter iPP-g-PNIPAAm for simplification) were dried at $30{ }^{\circ} \mathrm{C}$ overnight under vacuum. The aspect of the PP mesh after PNIPAAm/MBA covalent bonding is completely transparent, as shown in our previous study. ${ }^{11}$ 


\subsection{Physical-chemical characterization}

Detailed description of the methods used for the characterization of the iPP-g-PNIPAAm mesh prepared in this work is provided in the ESI. $\dagger$ Specifically, the following characterization techniques were employed: Fourier-transform infrared spectroscopy (FTIR); X-ray photoelectron spectroscopy (XPS); field emission scanning electron microscopy (FE-SEM); atomic force microscopy (AFM) and confocal fluorescence microscopy. The procedures for the evaluation of the swelling ratio (ESR) and the graft yield (GY) are also described in the ESI. $\dagger$

\subsection{Biological studies}

Cellular assays were performed using epithelial (MCF-7) and fibroblast (COS-1) cells. Such cell lines were selected due to their well-known rapid growth and origin from soft tissues. Untreated and plasma treated Optilene ${ }^{\mathbb{R}}$ mesh LP as well as iPP- $g$-PNIPAAm samples with an area of $1 \times 1 \mathrm{~cm}^{2}$ were used. Control experiments were simultaneously performed for the evaluation of the cell adhesion and cell proliferation for comparison with other systems. The whole procedure is described in the ESI. $\dagger$

\section{Results and discussion}

\subsection{Effect of the crosslinker concentration on the composition and swelling properties of iPP- $g$-PNIPAAm platforms}

In order to analyse the influence of MBA concentration in the graft yield and swelling degree, a series of reactions was carried out at $30{ }^{\circ} \mathrm{C}(20 \mathrm{~h})$ using the NIPAAm monomer constant concentration of $250 \mathrm{mM}$, APS/TEMED $=1: 1([\mathrm{APS}]=2.77 \mathrm{mM})$ and varying the crosslinker concentration (1,2 and $4 \mathrm{mM})$.

FTIR spectra reported in Fig. 1 showed several changes after grafting, if compared with the Optilene ${ }^{\circledR}$ mesh LP functionalized by plasma. Firstly, a number of new $\mathrm{N}$ - and O-containing groups were successfully introduced on the iPP mesh surface through the grafting reaction during the polymerization process, coming from PNIPAAm chains. Bands observed in the range $3200-3600 \mathrm{~cm}^{-1}$ (labelled as 1 and 2) are attributed to $-\mathrm{OH}$ groups and to the stretching vibration of- $\mathrm{NH}_{2}$, respectively. ${ }^{37}$ Secondly, the spectra

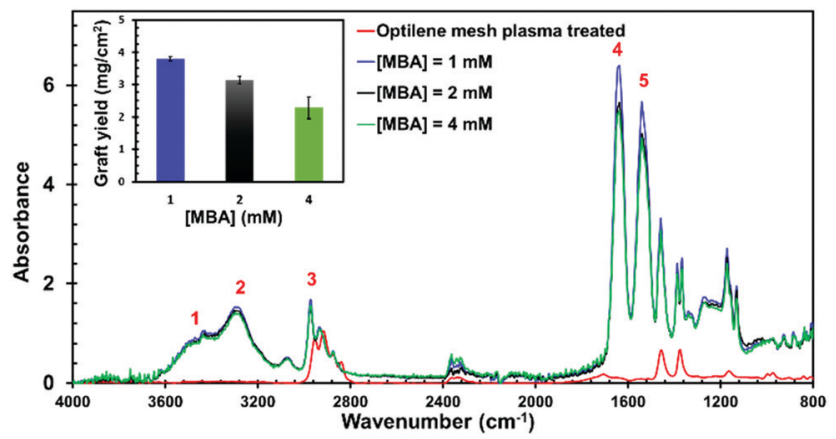

Fig. 1 FTIR spectra and graft yield (inset) of the Optilene ${ }^{\circledR}$ mesh LP-gPNIPAAm/MBA grafted copolymer at different [MBA] concentrations (from $1 \mathrm{mM}$ to $4 \mathrm{mM}$ ). The grafting reaction time is $20 \mathrm{~h}$. The numbers in the inset refer to the absorption bands of: (1) hydroxyl; (2) amine; (3) $\mathrm{C}-\mathrm{H}$ from methylene and methyl; (4) amide I; and (5) amide II groups. of the grafted samples show the characteristic absorption bands at about $2800-3000 \mathrm{~cm}^{-1}$, which are attributed to the stretching vibration of $-\mathrm{CH}_{2}$ groups in the iPP backbone, covered by the band of - $\mathrm{CH}$ stretching of PNIPAAm at $2970 \mathrm{~cm}^{-1}$ (labelled as 3). ${ }^{38}$ Finally, in all cases, the grafted samples exhibit characteristic absorption bands of PNIPAAm with sharp and strong intensities at wavenumbers of $1640 \mathrm{~cm}^{-1}(4, \mathrm{C}=\mathrm{O}$ stretching of amide I) and $1540 \mathrm{~cm}^{-1}\left(5, \mathrm{~N}-\mathrm{H}\right.$ bending of amide II). ${ }^{38}$

As shown in the inset of Fig. 1, the GY, calculated using eqn (S1) (ESI $\dagger)$, decreases with increasing MBA concentration in the polymerization medium. The GYs obtained for 1, 2 and $4 \mathrm{mM}$ MBA were $3.89 \pm 0.12,3.14 \pm 0.12$ and $2.28 \pm 0.33 \mathrm{mg} \mathrm{cm}^{-2}$, respectively. This behaviour is explained by the reactivity of MBA, which acts as a water-soluble co-monomer. The amount of NIPAAM monomer reacting with MBA in the bulk of the solution increases with the crosslinker concentration, thus decreasing its concentration at the interface between the iPP mesh and the aqueous solution.

Both experiments demonstrated that the iPP plasma treated surface is covered by the covalently attached gel, even when the lowest content of crosslinker was used ( $1 \mathrm{mM})$.

As the hydrogel porous networks present structures with different morphology and pore sizes, depending on the crosslinker concentration, it was necessary to study the morphology of the cross-section of the bilayer system to correlate the amount of hydrogel with the swelling properties, which is of fundamental relevance for the mechanical actuation of the whole system under temperature variation. Fig. 2 shows representative SEM micrographs of the Optilene ${ }^{\circledR}$ mesh LP- $g$-PNIPAAm films (freeze-dried), obtained in the presence of different crosslinker contents (1, 2 and $4 \mathrm{mM}$,). Shaped pores with large dimensions
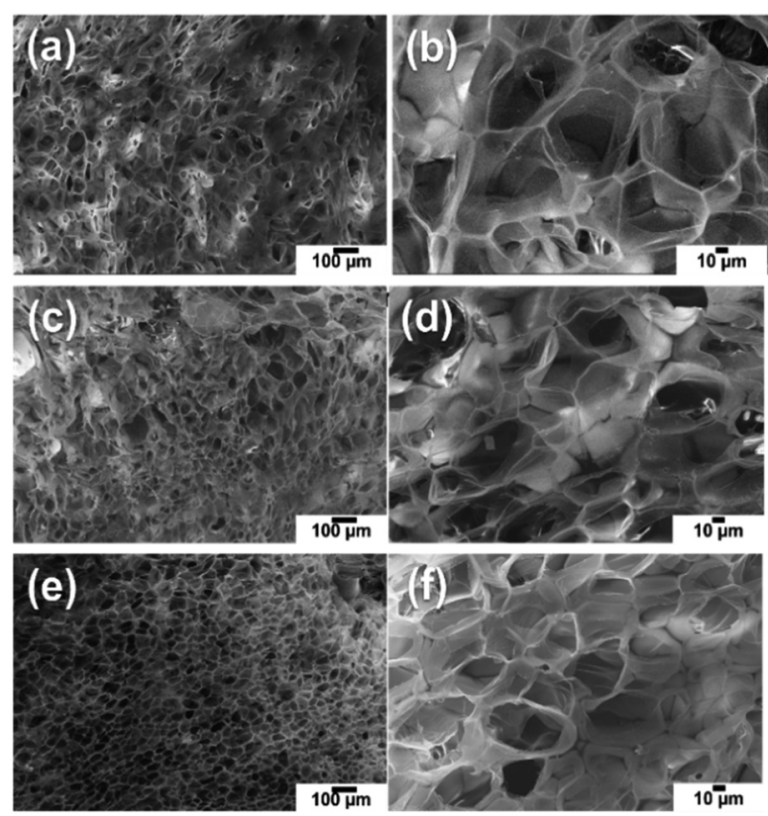

Fig. 2 SEM micrographs of the Optilene ${ }^{\mathbb{R}}$ mesh LP-g-PNIPAAm samples at different crosslinker concentrations: ( $a$ and b) $1 \mathrm{mM}$, (c and d) $2 \mathrm{mM}$ and (e and f) $4 \mathrm{mM}$. Cross sections obtained after freeze-drying. The grafting reaction time is $20 \mathrm{~h}$. 
were observed when a low concentration of MBA was used (Fig. 2a and b). Thus, the average pore size, which was determined using random locations from three micrographs, was $76 \pm 17,56 \pm$ 13 and $45 \pm 8 \mu \mathrm{m}$ with 1,2 and $4 \mathrm{mM}$ MBA, respectively. The standard deviation of pore size, which must be considered as an indicator of the homogeneity of pore distribution, decreases with increasing MBA content (i.e. more uniform pores appeared). Moreover, the PNIPAAm-co-MBA hydrogels present a well interconnected pore structure, which is beneficial for water transfer and, consequently, for the thermoresponsive behaviour of the iPP-g-PNIPAAm platforms.

On the other hand, the ESR (eqn (S2), ESI $\dagger$ ) of all samples was measured in a water bath, from $25{ }^{\circ} \mathrm{C}$ to $40{ }^{\circ} \mathrm{C}$ for $24 \mathrm{~h}$, to evaluate the amount of absorbed water. Temperature-dependent equilibrium swelling ratio is shown in Fig. 3. The results show that the MBA concentration is an effective variable for the swelling behaviour, particularly in the low temperature region (below $30{ }^{\circ} \mathrm{C}$ ). The highest swelling ratio is obtained with the hydrogel produced with the lowest MBA content. On the other hand, the equilibrium of water content of all hydrogels, with different MBA concentrations, was the same at temperatures higher than $35{ }^{\circ} \mathrm{C}$, as expected, once the system overcomes the PNIPAAm LCST temperature.

The crosslinking density is not the factor controlling the equilibrium water content of PNIPAM hydrogels in the shrunken state since the gel behaviour is predominantly dominated by the hydrophobic interactions. The higher ability to hold water in the iPP- $g$-PNIPAAm mesh with the lowest MBA concentration has been attributed to the bigger dimensions of the pores, as observed by SEM micrographs. The ESR at $25{ }^{\circ} \mathrm{C}\left(\mathrm{ESR}_{25^{\circ} \mathrm{C}}\right)$ and at $40{ }^{\circ} \mathrm{C}$ $\left(\mathrm{ESR}_{40^{\circ} \mathrm{C}} \mathrm{C}\right.$ has been used to evaluate the amount of water desorbed by the iPP- $g$-PNIPAAM mesh:

$$
\text { Amount of water desorbed }(\%)=\frac{\mathrm{ESR}_{25^{\circ} \mathrm{C}}-\mathrm{ESR}_{40^{\circ} \mathrm{C}}}{\mathrm{ESR}_{25^{\circ} \mathrm{C}}}
$$

This amount of water is connected with the variation in the volume of the gel associated with the shrinkage at high temperature. More specifically, the percentages of desorbed

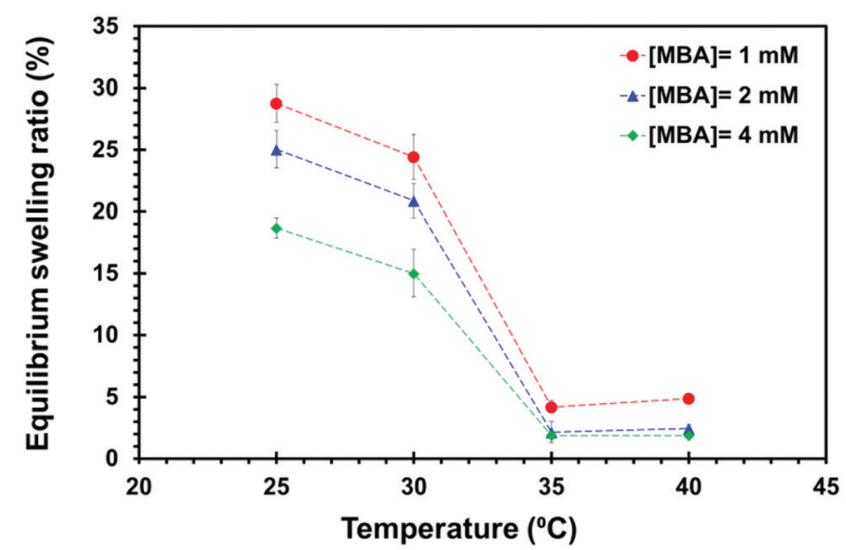

Fig. 3 Effect of crosslinking concentration on the variation of the equilibrium swelling ratio with the temperature. The grafting reaction time was maintained at $20 \mathrm{~h}$ and the [MBA] content varied from $1 \mathrm{mM}$ to $4 \mathrm{mM}$. water are $83.03 \%, 90.15 \%$ and $90.04 \%$ for samples grafted with $1 \mathrm{mM}, 2 \mathrm{mM}$ and $4 \mathrm{mM}$ MBA crosslinker, respectively. Thus, a quite constant value is reached for a crosslinker concentration $>2 \mathrm{mM}$. Besides, when the concentration of the crosslinker is the lowest $(1 \mathrm{mM})$, the amount of water desorbed decreased (83.03\%), which has been attributed to the greater amount of hydrophilic interactions in the presence of more water.

\subsection{Influence of the grafting time on the composition and swelling properties of iPP- $g$-PNIPAAm platforms}

In this section, the effect of the polymerization time is investigated. The concentrations of NIPAAm monomer and crosslinker were maintained constant $(250 \mathrm{mM}$ and $1 \mathrm{mM}$, respectively), whereas reaction times of 1, 2, 4 and $20 \mathrm{~h}$ were tested. In order to obtain the largest pores, which are expected to be more effective for future biomedical applications, the concentration of the crosslinker was kept at $1 \mathrm{mM}$. FTIR spectra (Fig. 4) show that the absorbance of PNIPAAm bands increases with time until $4 \mathrm{~h}$, whereas they are almost unaltered for samples treated either for $4 \mathrm{~h}$ or $20 \mathrm{~h}$ of graft polymerization. The kinetic graph provided in the inset of Fig. 4 indicate that the amount of grafted PNIPAAm reaches a maximum at $4 \mathrm{~h}$, confirming the trend observed in the IR spectra. The GYs (eqn (S1), ESI $\dagger$ ) obtained for grafting times of $1 \mathrm{~h}, 2 \mathrm{~h}, 4 \mathrm{~h}$ and $20 \mathrm{~h}$ were $0.26 \pm 0.05,0.91 \pm 0.19,4.22 \pm 0.34$ and $3.89 \pm$ $0.12 \mathrm{mg} \mathrm{cm}^{-2}$, respectively.

For obtaining more evidence of the surface composition, XPS was employed to confirm the grafting of the hydrogel onto the iPP mesh. Fig. 5a shows the XPS survey spectra of the Optilene ${ }^{\circledR}$ mesh LP- $g$-PNIPAAm samples after grafting reaction of $1 \mathrm{~h}$ and $2 \mathrm{~h}$. The intensity of the peak centred at $399.6 \mathrm{eV}$, which corresponds to $\mathrm{N} 1 \mathrm{~s}$, increases with grafting time (inset). Besides, no evident difference is detected in the position and intensity of the peaks centred at 285.1 and $533.1 \mathrm{eV}$ (C 1s and $\mathrm{O}$ $1 \mathrm{~s}$, respectively). As the mesh substrates have large pores, peaks related to the holder employed to support the samples (Al made) appear in Fig. 5a. ${ }^{39}$

In order to better understand the main functional groups present on the grafted mesh surface, the deconvolution of $\mathrm{C} 1 \mathrm{~s}$,

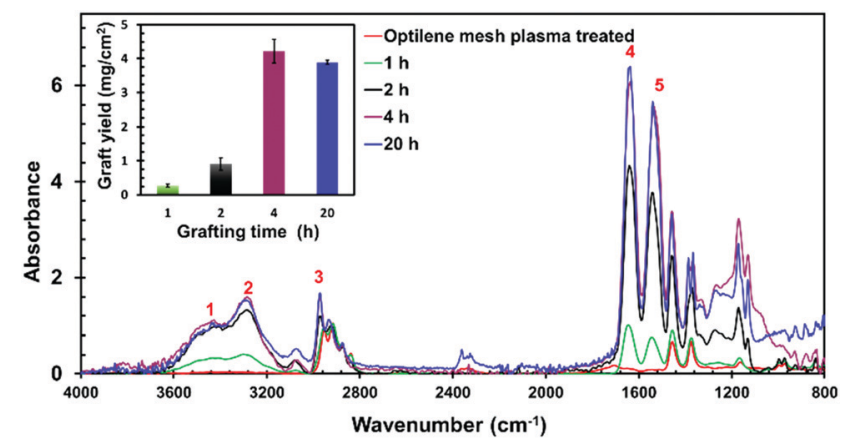

Fig. 4 FTIR spectra and graft yield (inset) of Optilene ${ }^{\mathbb{R}}$ mesh LP- $g$-PNIPAAm grafted copolymer at different grafting reaction times and a constant [MBA] concentration. The numbers in the inset refer to the absorption bands of: (1) hydroxyl; (2) amine; (3) $\mathrm{C}-\mathrm{H}$ from methylene and methyl; (4) amide I; and (5) amide II groups. 

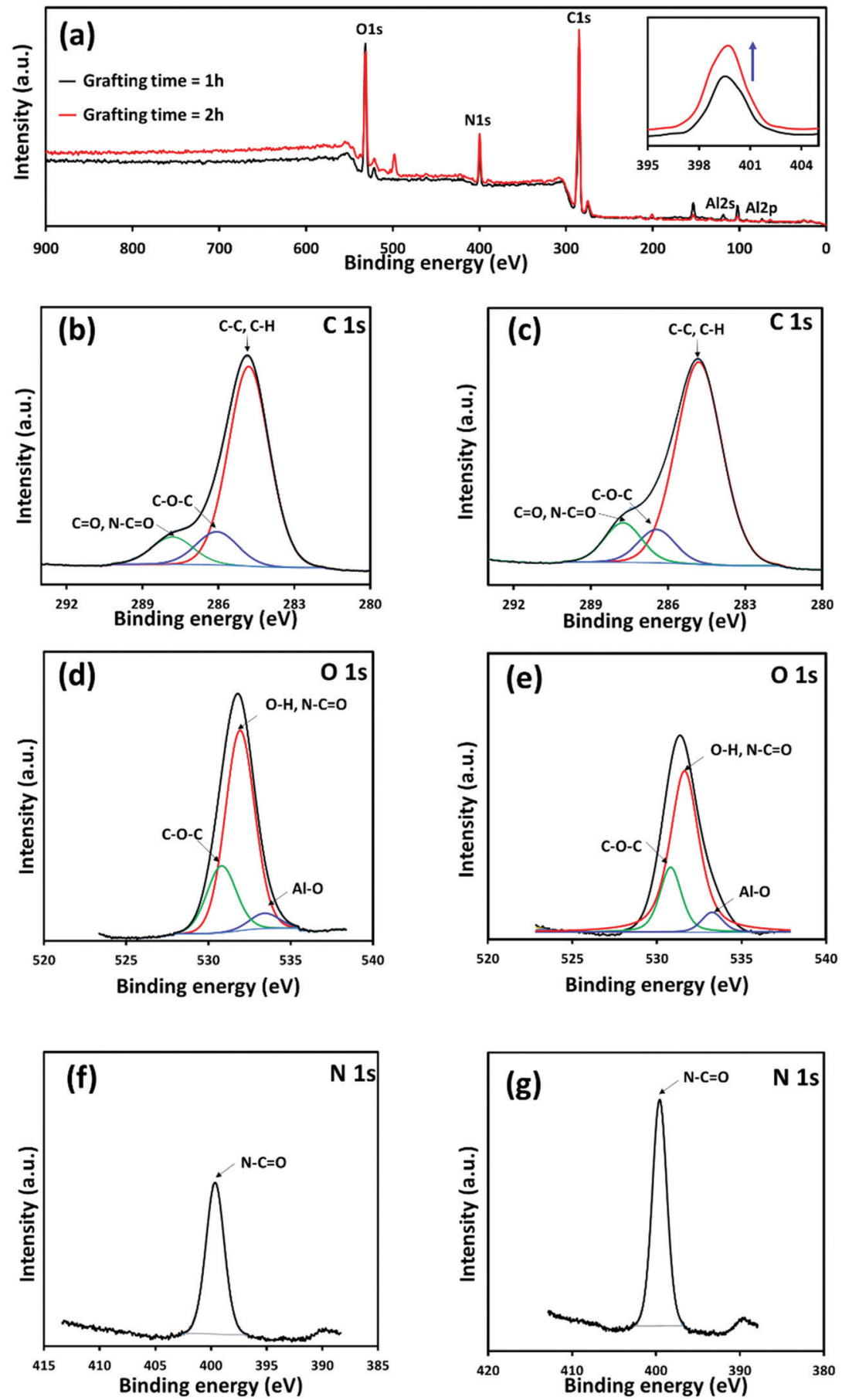

Fig. 5 (a) XPS survey spectra of the Optilene ${ }^{\mathbb{R}}$ mesh LP-g-PNIPAAm samples after grafting reaction carried out for 1 and $2 \mathrm{~h}$. High resolution XPS spectra of $\mathrm{C} 1 \mathrm{~s}, \mathrm{O} 1 \mathrm{~s}$ and $\mathrm{N} 1 \mathrm{~s}$ elements for samples grafted for $1 \mathrm{~h}(\mathrm{~b}-\mathrm{f})$ and $2 \mathrm{~h}(\mathrm{c}, \mathrm{e}$ and $\mathrm{g}$ ). Blue arrow in the inset of (a) indicates the increase in the $\mathrm{N} 1 \mathrm{~s}$ atomic concentration from PNIPAAm after $2 \mathrm{~h}$ of reaction time.

$\mathrm{O} 1 \mathrm{~s}$ and $\mathrm{N} 1 \mathrm{~s}$ peaks was carried out. Fig. 5b-g show the high resolution XPS spectra of $\mathrm{C} 1 \mathrm{~s}, \mathrm{O} 1 \mathrm{~s}$ and $\mathrm{N}$ 1s elements for iPP-gPNIPAAm grafted in $1 \mathrm{~h}$ (Fig. $5 \mathrm{~b}, \mathrm{~d}$ and f) and $2 \mathrm{~h}$ (Fig. $5 \mathrm{c}$, e and g). The atomic concentration of each chemical component was calculated and the results are displayed in Table S1 (ESI $\dagger$ ). It can be seen that for C $1 \mathrm{~s}$ spectra (Fig. $5 \mathrm{~b}$ and c), Optilene ${ }^{\mathbb{R}}$ mesh LP-gPNIPAAm copolymers exhibit three peaks at $284.8 \mathrm{eV}$ (C-C, C-H), $286.1 \mathrm{eV}(\mathrm{C}-\mathrm{O}-\mathrm{C})$ and $287.81 \mathrm{eV}(\mathrm{C}=\mathrm{O}, \mathrm{N}-\mathrm{C}=\mathrm{O})$, due to the surface layer of PNIPAAm grafted onto the mesh fibres. The spectra and the relative deconvolution are quite similar for the two grafting times, with the exception of the peak centred at $287.8 \mathrm{eV}$ that is more intense for the system obtained fusing for the longest time. Fig. $5 \mathrm{~d}$ and e displays the high resolution $\mathrm{O}$ 1s spectra and the relative deconvolution. All the atomic concentrations have been calculated subtracting the amounts of $\mathrm{C}$ and $\mathrm{O}$ detected in the holder (Al). The $\mathrm{O}$ 1s atomic 
concentration is 15.31 and $13.78 \%$ (Table $\mathrm{S} 1$, ESI $\dagger$ ) for samples grafted for $1 \mathrm{~h}$ and $2 \mathrm{~h}$, respectively. This reduction has been attributed to the higher amount of gel, which almost fills the pores between fibres, decreasing the signal coming from the holder. A similar explanation could be applied for the change in the $\mathrm{C} 1 \mathrm{~s}$ atomic concentration, which decreases from 78.09 to $77.49 \%$ for samples grafted during 1 and $2 \mathrm{~h}$, respectively. On the other hand, the atomic concentrations of $\mathrm{Al}$ decreased from $2.83 \%$ to $0.55 \%$ for samples with hydrogel deposited for 1 and $2 \mathrm{~h}$, respectively, confirming the screening effect of the PNIPAAm/MBA gel when a longer time was employed.

Fig. 5f, $g$ and Table S1 (ESI $\dagger$ ) show that the intensity of the peak centred at $399.6 \mathrm{eV}(\mathrm{N}-\mathrm{C}=\mathrm{O})$ is clearly higher when $2 \mathrm{~h}$ of grafting time was employed, reflecting a greater amount of $\mathrm{N} 1 \mathrm{~s}$ $(8.73 \%)$ compared to the system obtained using $1 \mathrm{~h}(6.59 \%)$. The N/O ratio also confirms the higher amount of gel after $2 \mathrm{~h}$ of grafting, varying from 0.43 to 0.63 , while $\mathrm{O} / \mathrm{C}$ and N/C ratios remained almost constant. Table $\mathrm{S} 2$ (ESI $\dagger$ ) summarizes the atomic concentration of the main functional groups derived from the deconvolution of $\mathrm{O} 1 \mathrm{~s}$ spectra.

\subsection{Effect of grafting time for the deposition of PNIPAAm on the 2D-geometry of the monofilament polypropylene mesh}

Following the previous results, ${ }^{11}$ in this section, we prove that the control of the polymerization time is of fundamental relevance to get not only iPP fibres with hydrogel covalently bonded to the PP matrix, but also with mesh pores free of hydrogel. Like in Section 3.1, the effects of the grafting time on the gel deposition and morphology were examined by using optical microscopy and SEM. Fig. 6 shows representative SEM micrographs of the Optilene ${ }^{\circledR}$ mesh LP-g-PNIPAAm samples freeze-dried (Fig. 6a-d) and optical images of samples dried under vacuum at $30{ }^{\circ} \mathrm{C}$ (Fig. 6e-h). It is important to clarify that the samples for SEM analysis were previously freeze-dried, whereas the samples for optical microscopy were dried under vacuum ( $24 \mathrm{~h}, \mathrm{RT})$. This is the reason why the lower images are transparent to optical reflection and the PP monofilaments can be easily observed, whereas in SEM, this is not readily accessible, particularly when the thickness of the hydrogel is high. More specifically, the micrographs of SEM and optical microscopy correspond to samples treated for $1 \mathrm{~h}$ (Fig. 6a and e), $2 \mathrm{~h}$ (Fig. 6b and f), $4 \mathrm{~h}$ (Fig. 6c and g) and $20 \mathrm{~h}$ (Fig. 6d and h). After $1 \mathrm{~h}$ of polymerization (Fig. 6a and e), the non-porous PNIPAAm hydrogel forms in the areas adjacent to the iPP fibres only (indicated by arrows in Fig. 6a), whereas the pores of the mesh remain completely empty. The samples obtained after a longer reaction time present not only a much greater amount of hydrogel, as discussed in Section 3.2, but also a noticeable difference in its morphology and distribution. After $2 \mathrm{~h}$ of grafting (Fig. 6b and f), a porous gel that almost fills the entire volume of the mesh pores (indicated by arrows in Fig. 6b) and connects the iPP fibres is observed. An interesting characteristic of this hydrogel is the presence of big holes (indicated as circles in Fig. 6b). As recently reported by Hou et al., ${ }^{40}$ the presence of spaces between microgels helps neighboring cells to move easily through them. These authors engineered a highly biofunctional injectable macroporous hydrogel made of gelatin microgels crosslinked by microbial transglutaminase (mTG), creating pores among the microgels to promote cell migration. In the particular case of meshes for hernia repair, mesh pores free of gel are also of primary relevance due to the need of abdominal wall adhesion and immobilization. However, as shown in Fig. 6, after $4 \mathrm{~h}$ of grafting, the mesh pores are completely covered by the gel, whereas the iPP fibres still remain visible. Therefore, polymerization times between 1-2 $\mathrm{h}$ are the best options to avoid obstruction of mesh pores.

Although the presence of PNIPAAm molecules on iPP mesh fibres with low polymerization time $(1 \mathrm{~h})$ was proved by FTIR; Raman and XPS, and a combination of SEM, focused ion beam (FIB) sectioning and AFM assays were conducted (Fig. 7). After $1 \mathrm{~h}$, there is a thin layer of PNIPAAm chains that grows on top of the fibre, at the surface (Fig. 7a). The deposition is not
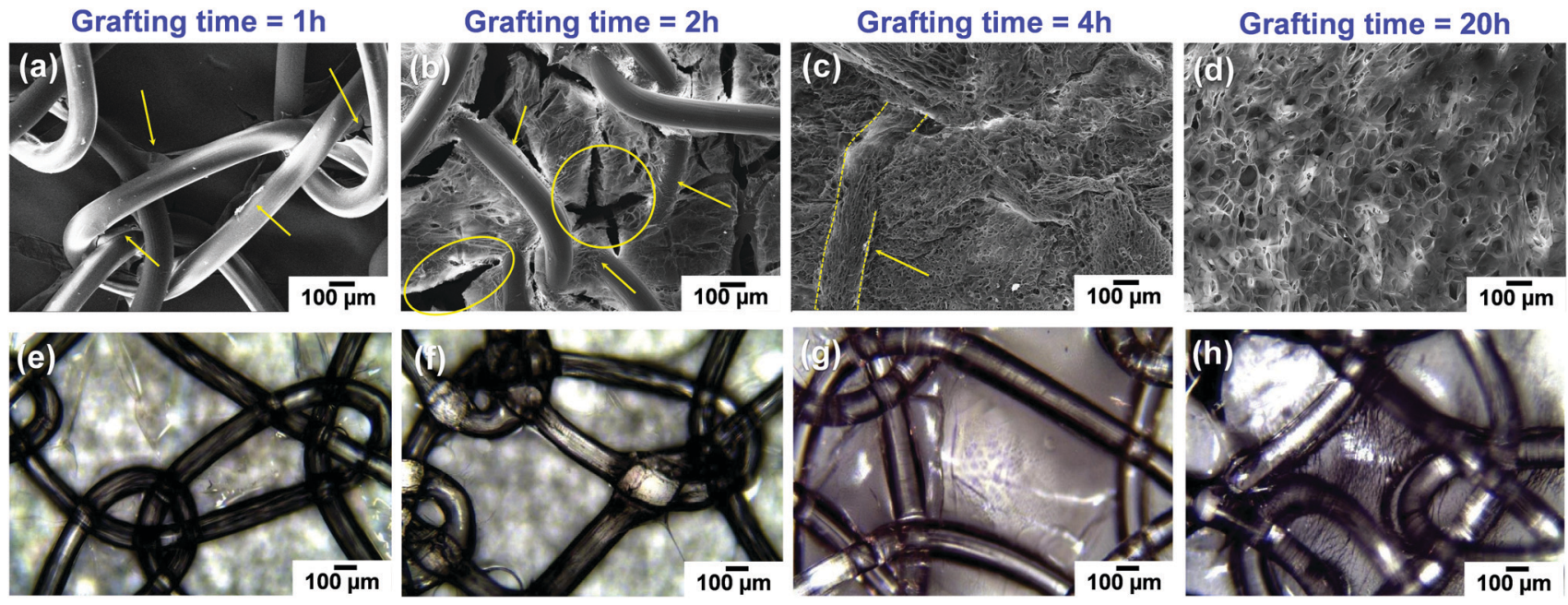

Fig. 6 SEM micrographs (upper) and optical images (down) of the Optilene ${ }^{\circledR}$ mesh LP- $g$-PNIPAAm samples at different grafting times: (a and e) $1 \mathrm{~h}$, (b and f) $2 \mathrm{~h}$, (c and g) $4 \mathrm{~h}$ and ( $\mathrm{d}$ and h) $20 \mathrm{~h}$. Samples for SEM analysis were previously freeze-dried, whereas samples for optical microscopy were dried under vacuum $(24 \mathrm{~h}, \mathrm{RT})$. Yellow arrows and circles in (a) and (b) indicate the deposition of PNIPAAm over iPP monofilaments and the presence of holes in the hydrogel film, respectively. 
(a) SEM

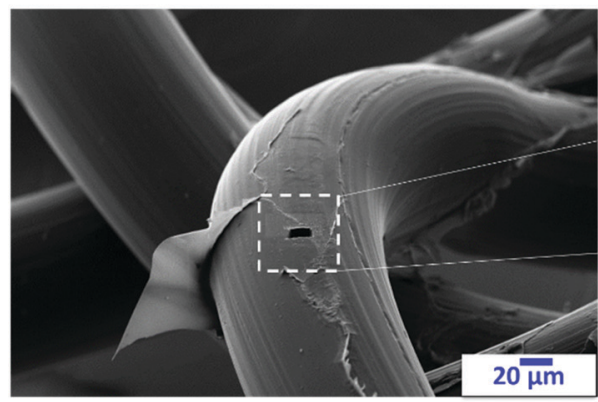

(b) FIB cross sectioning

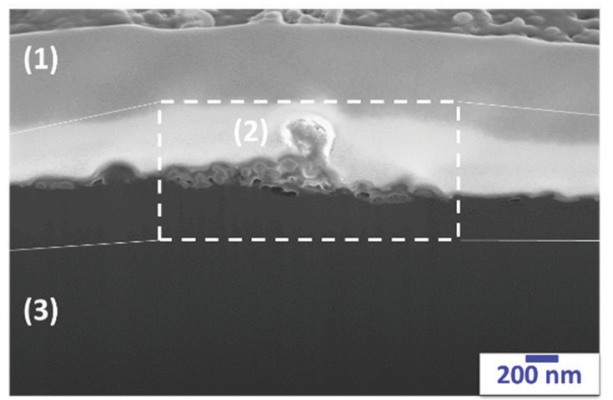

(c) AFM

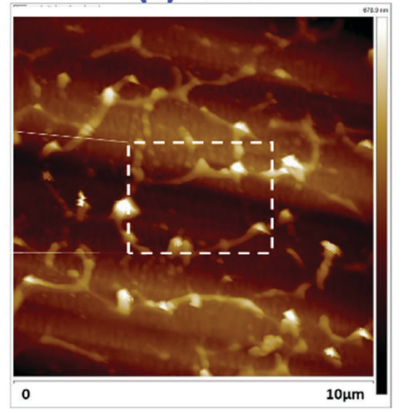

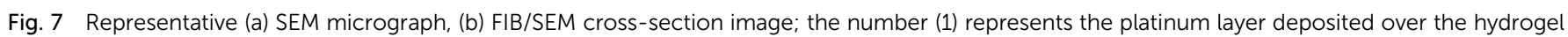

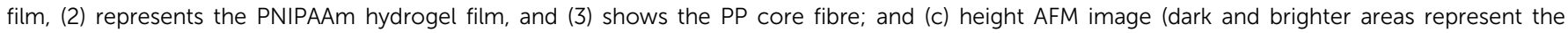

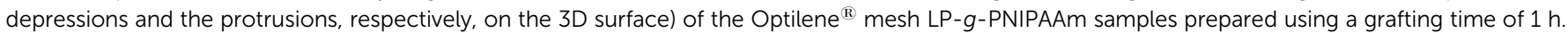

homogenous and some regions are not completely covered (Fig. 7b). Height AFM images (Fig. 7c) indicate that PNIPAAm chains grow perpendicularly to the fibre surface. Instead, after $2 \mathrm{~h}$ of PNIPAAm deposition, the fibres are fully covered by the hydrogel, which starts to expand among the mesh pores. Finally, the pores are completely covered after 4 and $20 \mathrm{~h}$ of reaction (additional discussion and AFM images are included in the ESI, $\dagger$ Fig. S1).

In summary, for the specific application, the Optilene ${ }^{\circledR}$ mesh LP-g-PNIPAAm grafted for $2 \mathrm{~h}$ seems to be the most appropriate in order to promote both cell migration and the abdominal wall interaction, as previously discussed.

\subsection{In vitro cell culture studies}

Optilene ${ }^{\mathbb{R}}$ mesh LP grafted with PNIPAAm is intended to be nontoxic and preferably with modulating adhesive/anti-adhesive behaviour to avoid post-operatory inflammation caused by the adherence of the mesh with visceral organs. Pristine and plasma treated Optilene ${ }^{\circledR}$ mesh LP as well as Optilene ${ }^{\mathbb{R}}$ mesh LP- $g$ PNIPAAm platforms were tested in the presence of fibroblast and epithelial-like cell lines (COS-1 and MCF-7, respectively) to study their cytotoxicity and cell adhesion. Inspection of Fig. 8, which shows cell viability after $24 \mathrm{~h}$ (cell adhesion) and 7 days (cell proliferation), reveals a clear dependence of the cell viability on both the porous network of the hydrogel (i.e. the concentration of the crosslinker) and the grafting time.

When a high content of hydrogel was covalently bonded to iPP platforms (i.e. after $20 \mathrm{~h}$ of polymerization reaction, corresponding to a GY of $3.89 \pm 0.12 \mathrm{mg} \mathrm{cm}{ }^{-2}$ ), cell adhesion and proliferation ( 7 days) were practically independent of the MBA content, as shown in Fig. 8a. Thus, differences, which were very small, have been attributed to the pore sizes, which were smaller for the hydrogel with $4 \mathrm{mM}$ MBA (Fig. 2e and f) than for the other MBA contents. Instead, no difference between the untreated iPP mesh and that treated with plasma radiation, in terms of cell adhesion and cell proliferation, was observed; corroborating that hydrogel pores play an important role in this behaviour.

The results showed a drastic change when a low grafting time was employed (Fig. 8b and c), upon comparing the two cell lines. The epithelial cells (MCF-7) show remarkable affinity towards the iPP-g-PNIPAAm porous network after $24 \mathrm{~h}$, but proliferation after 7 days was low (Fig. 8b). Regarding the fibroblast-like cells, the adhesion increased for the plasma treated iPP and the bilayer system (either for 1 or $2 \mathrm{~h}$ of gel deposition) with respect to the untreated iPP meshes, whereas cell proliferation decreased for the latter samples (Fig. 8c). In summary, cell adhesion is strongly dependent on the pore size of the PNIPAAm adhered to the PP mesh and it has a preference towards epithelial cells (Fig. 8b) when compared to fibroblast cells (Fig. 8c).

Special attention and discussion are required to address the effect of the grafting time on the proliferation of both fibroblast- and epithelial-like cells. As shown in Fig. 8b and c, cell proliferation on the mesh decreases upon increasing grafting time, similar to what happens for cell adhesion. Two possible explanations for such adhesion- and de-adhesion mechanisms have been reported in the literature. ${ }^{28-30,37,41}$ It is well-known that ether groups are effective at repelling cells and proteins ${ }^{42}$ and, as shown above by XPS (Fig. 5), new $\mathrm{C}-\mathrm{O}-\mathrm{C}$ groups appeared as a result of the bond created by the grafting reaction between the hydroxyl groups on the plasma treated mesh surface and the NIPAAm monomer. ${ }^{11}$ The presence of this group could be responsible for the de-adhesion of cells detected when the bilayer system (mesh and PNIPAAm/MBA) was left over 7 days in contact with them, with respect to the samples without PNIPAAm. Table S2 (ESI $\dagger$ ) reports the atomic concentration of oxidative functional groups obtained by peak deconvolution of $\mathrm{O}$ 1 s from XPS measurements, showing that the $\mathrm{C}-\mathrm{O}-\mathrm{C}$ group concentration increased from $5.48 \%$ to $8.02 \%$ when the grafting time changed from $1 \mathrm{~h}$ to $2 \mathrm{~h}$. This result corroborates the assumption that the amount of reactive sites interacting with the monomer increases with the grafting time, which is consistent with the observed cell repelling behavior. Nevertheless, the ether linkages located at the interface between the iPP fibres and the PNIPAAm chains are scarcely accessible because of the high thickness of the hydrogel. Prompted by this consideration, another possible explanation could be taken proposed. PNIPAAm-based thermoresponsive surfaces can switch their wettability (from wettable to non-wettable) and adhesion (from sticky to non-sticky) according to external temperature changes, as described in earlier pioneering works. ${ }^{31,43}$ This property is crucial and appealing for the applicability of the meshes because it permits the dynamical control of the adhesion to human tissues. By changing the temperature from $25{ }^{\circ} \mathrm{C}$ (environment temperature) to $37^{\circ} \mathrm{C}$ (incubator temperature), 

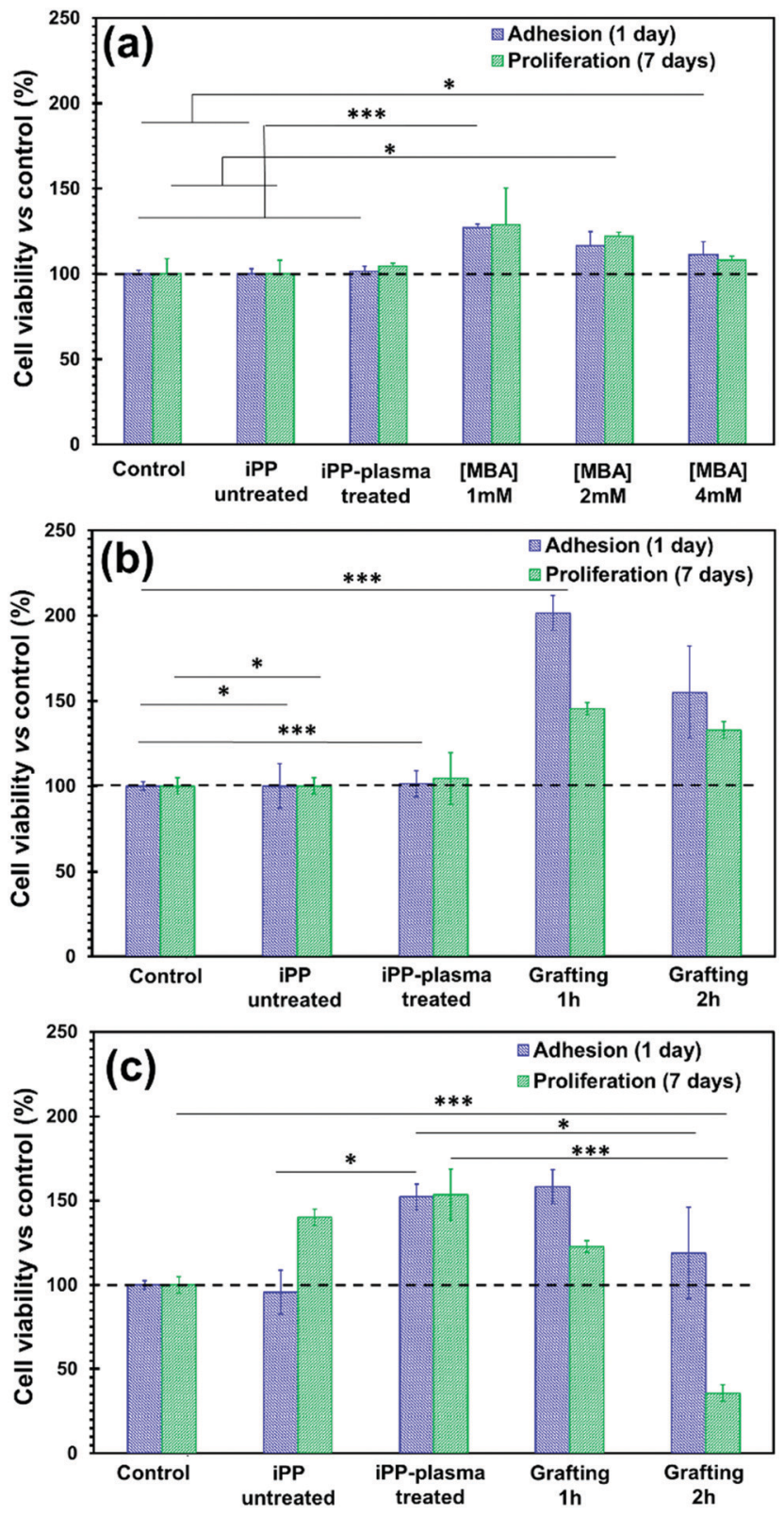

Fig. 8 (a) Percentage of MCF-7 cells adhered to iPP-g-PNIPAAm grafted meshes with different crosslinker contents and a constant grafting time (20 h). (b) Percentage of MCF-7 and (c) and COS-1 cells attached to iPP-g-PNIPAAm obtained at the lowest grafting times ( $1 \mathrm{~h}$ and $2 \mathrm{~h}$ ), with constant NIPAAm and MBA concentrations ( $250 \mathrm{mM}$ and $1 \mathrm{mM}$, respectively). Control refers to the stainless steel substrates alone, without PP mesh. In all cases, data correspond to the average of four independent assays with the standard deviation. Asterisk marks $\left(^{*}\right)$ and $\left({ }^{* * *}\right)$ represent significant difference among the samples at $p<0.05$ and $p<0.001$, respectively.

the conformation of PNIPAAm chains changes from expanded to globule, across the LCST. Above its LCST, the hydrophobic surface of PNIPAAm promotes adsorption of extracellular matrix (ECM) with subsequent cell adhesion, while below the LCST, the high water content in the hydration layer prevents the adsorption of proteins, promoting the detachment of the cells. ${ }^{37}$ This second explanation is relevant because in the previous sections (3.2 and 3.3), we have demonstrated that the grafting time influences the amount of hydrogel deposited, its morphology and its swelling properties. Therefore, the expanded and globule conformations are highly dependent on the grafting yield (GY).

Based on our results, it is possible to propose a mechanism of cell attachment and detachment as a function of grafting time (Fig. 9a-d) in the bilayer system composed by iPP commercial mesh and PNIPAAm hydrogel. Therefore, we proved that the grafting time is responsible for changes in the morphology of the hydrogel in terms of pore sizes, GY and distribution around the iPP fibres. When the highest grafting times are employed ( 4 and $20 \mathrm{~h}$ ), well defined and homogenous pores are obtained. Moreover, their dimensions are appropriate to allow cells to go inside the pores and proliferate there. This aliquot of cells remains inside the PNIPAAm pores, even below the LCST temperature (Fig. 9d), and they are not involved in the detachment process, which occurs only at the outer surface of the PNIPAAm layer. ${ }^{44}$ When the grafting time is lower than $4 \mathrm{~h}$ (Fig. 9b and c), the hydrogel porosity is not well defined and the cells cover the entire mesh and adhere onto its surface. Therefore, the cell adhesion is promoted at any time if the environment temperature reaches $T>$ LCST. In summary, cell adhesion and de-adhesion can be modulated by controlling the graft time of PNIPAAm deposition on the 2D-geometry iPP mesh surfaces.

Overall, two phenomena are observed: (i) surface adhesion of cells increases if the mesh is heated at $T>$ LCST (i.e., at an incubation temperature of $37{ }^{\circ} \mathrm{C}$ ) due to the presence of contracted PNIPAAm chains only on the iPP fibres, allowing the cells to adhere onto them or to pass across the iPP mesh pores. The number of cells passing through the mesh pores decreases with increasing amounts of grafted hydrogel $(2 \mathrm{~h})$, as illustrated in Fig. 9c and d; (ii) pore migration of cells at $T<$ LCST predominates due to the presence of expanded PNIPAAm chains with different lengths, according to the grafting time. Thus, the amount of cells detached from the gel surface enhances with the longest PNIPAAM chains $(4-20 \mathrm{~h})$, while the amount of cells able to cross the mesh diminishes. Instead, cell detachment was not observed from the iPP meshes without hydrogel and only treated with oxygen-plasma, independent of the cell lines (Fig. 8 and 9a). These features prove that the surface functionalized by plasma has more active chemical groups, enabling cell adhesion and cell migration, and this evidences that the network structure of the grafted PNIPAAm is solely responsible for the cell adhesion/de-adhesion phenomena, as was previously suggested for flat and micropatterned sheets. ${ }^{19}$

The use of stimuli responsive surfaces with switchable properties has been explored to prepare smart surfaces ${ }^{45}$ and smart membranes for efficient water-oil separation, ${ }^{46}$ coatings to prevent bacterial infection and fouling during biomaterial implantation ${ }^{47}$ among others. These kinds of smart surfaces have exhibited great potential for on-demand applications, as in therapeutic medicine. ${ }^{32,48}$ However, the fabrication of such advanced functional materials is complex, limiting their scale-up and commercialization. Here, we demonstrate an easy procedure to prepare a smart and scalable mesh implant with modulated cell adhesion and cell de-adhesion properties. 
Functional groups generated by $\mathrm{O}_{2}$-plasma PNIPAAm chains

\section{- MBA (crosslinking points)}

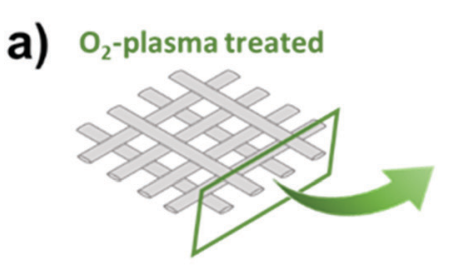

b)

Grafting time $=1 \mathrm{~h}$

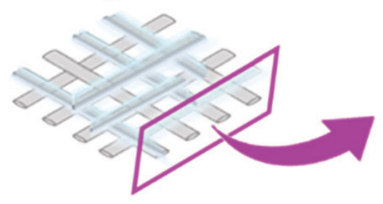

c)

Grafting time $=2 \mathrm{~h}$

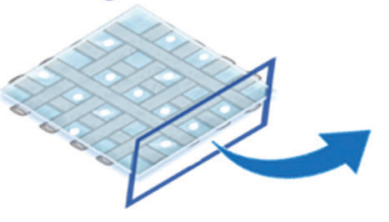

d)

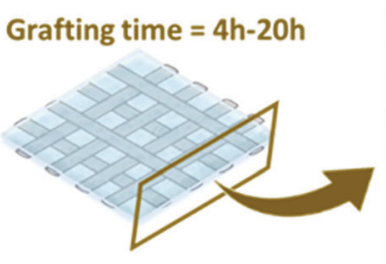

$\mathrm{T}<\operatorname{LCST}\left(25^{\circ} \mathrm{C}\right)$

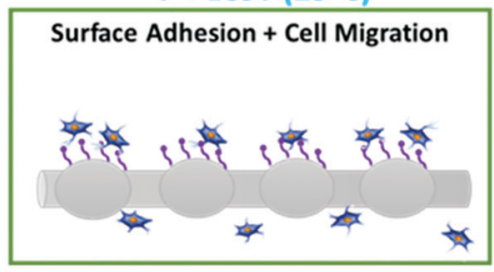

Surface Adhesion + Detachment + Cell
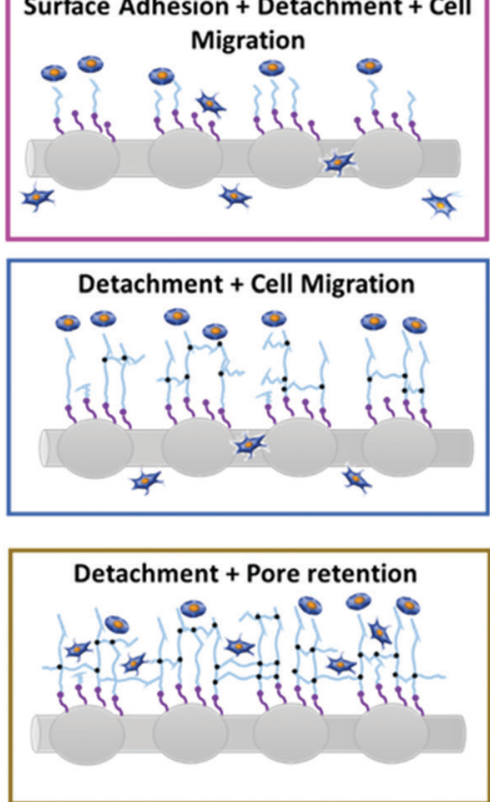
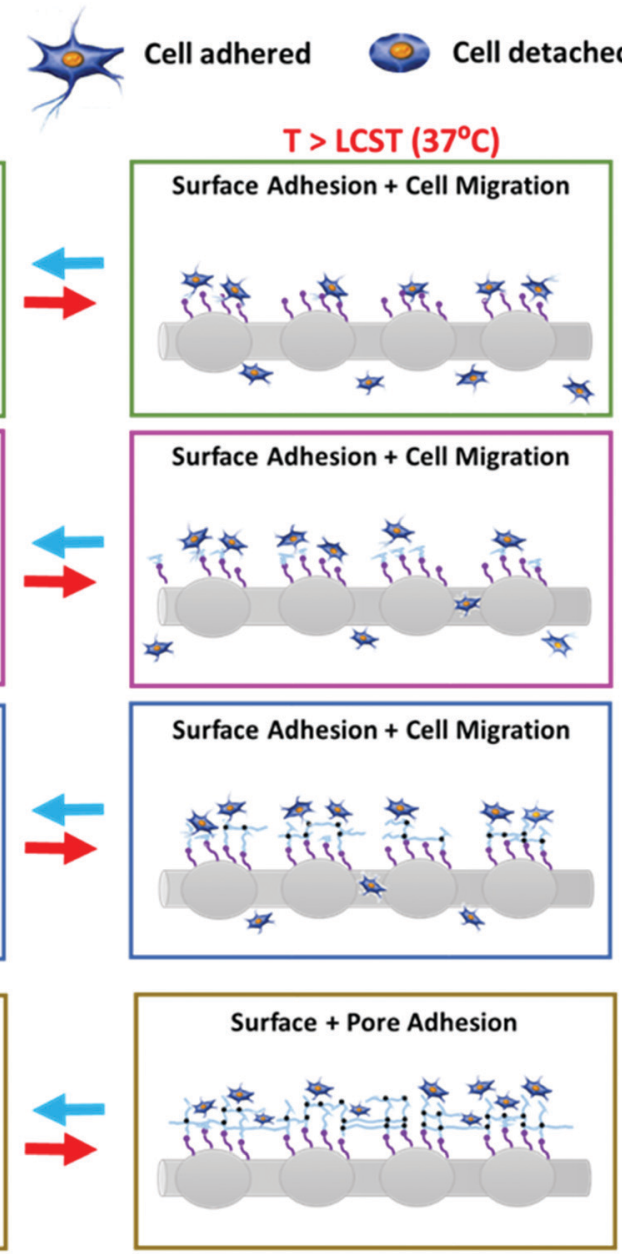

Fig. 9 Mechanism of cell adhesion and cell migration on iPP-g-PNIPAAm mesh, upon temperature changes (LCST $<T>$ LCST).

\subsection{Morphology of cells in the iPP-g-PNIPAAm mesh platforms}

In order to observe the morphology of the cells attached to the iPP mesh fibres grafted with PNIPAAm hydrogel and to explore in depth the detachment mechanism, confocal and optical microscopy images of MCF-7 and COS-1 cells were recorded. Fig. 10 shows representative micrographs in the presence of MCF-7 cells and after 7 days of cell culture (proliferation). Culture medium without mesh was used as a control (Fig. 10a and e). Compared with the untreated mesh (Fig. 10b and f), the plasma treated mesh (Fig. 10c and g) exhibits more expanded cells on its fibre surface. Functional groups found on this surface, for example, ketone and carboxyl groups, ${ }^{11}$ play a positive role in the cell adhesion, as previously stated by Canal and co-workers. ${ }^{49,50}$ Finally, the presence of the hydrogel (Fig. 10d and h) led to a noticeable change in the cell morphology, which looks spheroidal. The formation of such spheroid-like aggregates on this kind of hydrogel may be attributed to the relatively weak cell-substrate interaction as previously suggested by Gan et al. ${ }^{51}$ Therefore, the cells tend to aggregate via cell-cell interaction, instead of attaching to the hydrogel walls, and tend to be easily detached from the surface of the gel. When the hydrogel surface becomes more hydrophilic, the cell-substrate interaction becomes weaker. ${ }^{51}$
The morphology observed by confocal and optical microscopies is in good agreement with the results obtained by MTT assay and with the proposed detachment (Fig. 9).

Fig. 11 shows confocal images recorded in the presence of COS-1 cells, after 7 days of culture (proliferation). In the control (Fig. 11a and its magnification in Fig. 11b), cell agglomeration on the surface of the wells can be identified on the smooth surface, i.e., in the wells without mesh. Also, the plasma treated mesh is able to hold more cells (Fig. 11d) than the untreated one (Fig. 11c). Instead, few cells grew on iPP fibre surfaces when they were covered with the hydrogel (Fig. 11e, arrow inset), their detection being very difficult. These results are consistent with the very low amount of cells counted in Fig. 8b ( $2 \mathrm{~h}$ ). High magnification images taken directly on the gel surface show fluorescence inside the pores of the gel (Fig. 11f, arrows inset), corroborating that, although cells do not proliferate, they are trapped inside the pores. Based on these results, iPP-g-PNIPAAm was proved to be a biocompatible system with anti-adhesion properties. These results represent a significant advance since the utilization of iPP implants with one side able to fix the abdominal wall, while the other side covalently bonded to PNIPAAm hydrogel, able to avoid cell growth, is expected to avoid problems of recurrent 

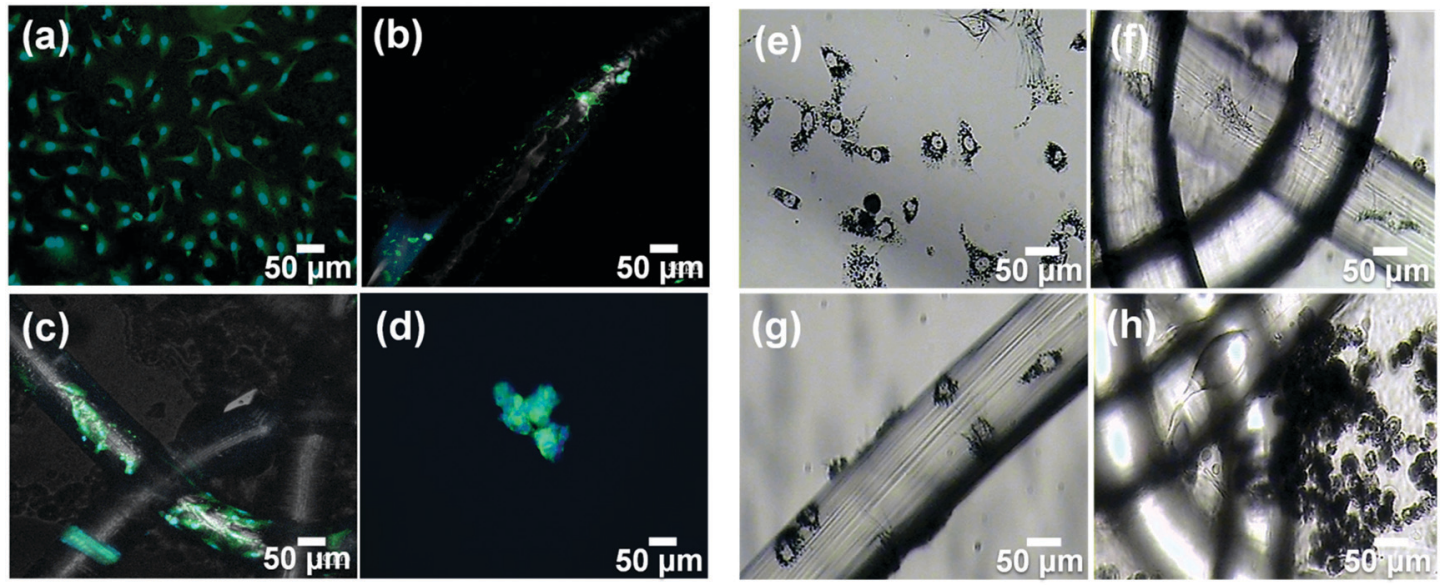

Fig. 10 Confocal laser scanning microscopy (on left) and optical microscopy (on right) micrographs of MCF-7 cells in the (a and e) culture media without mesh (control); (b and f) cultured on a pristine Optilene ${ }^{\circledR}$ mesh LP; (c and g) oxygen-plasma treated Optilene ${ }^{\mathbb{R}}$ mesh LP; and (d and h) Optilene ${ }^{\mathbb{R}}$ mesh LP-g-PNIPAAm grafted during $2 \mathrm{~h}$
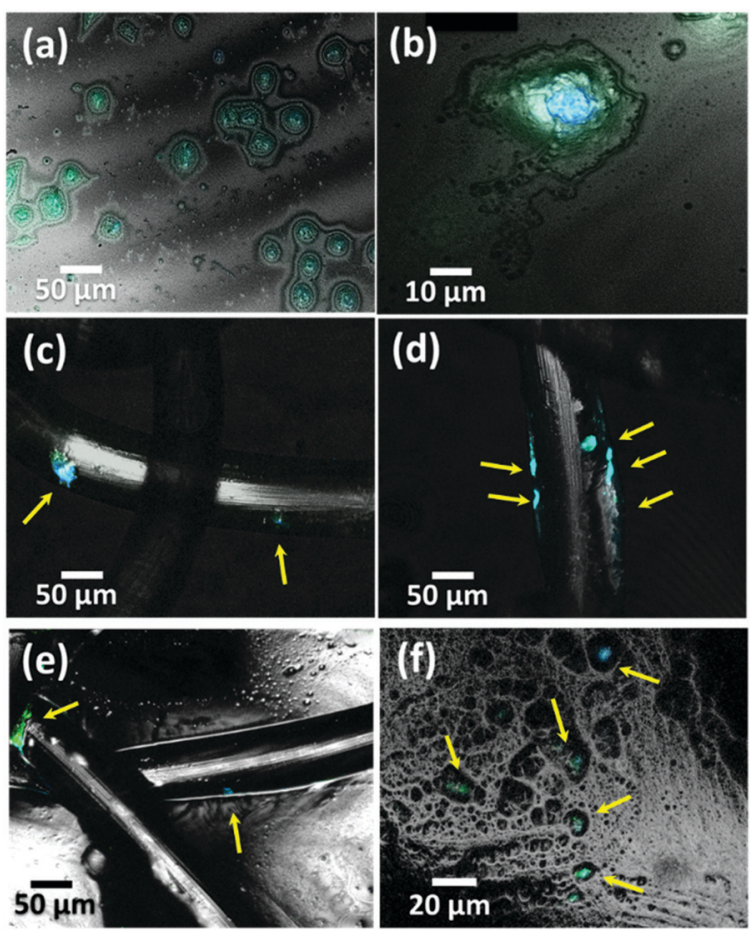

Fig. 11 Confocal laser scanning microscopy images of COS-1 cells ( $a$ and $b$ ) in the culture media without mesh (control), and cultured on untreated Optilene ${ }^{\mathbb{R}}$ mesh (c), plasma treated Optilene ${ }^{\mathbb{R}}$ mesh LP (d), and iPP-g-PNIPAAM grafted during $2 \mathrm{~h}$ (e and f). Yellow arrows indicate the presence of COS-1 cells.

surgery. Complementary SEM images from such samples are shown in Fig. 11e, f and also in Fig. S2 (ESI $\dagger$ ).

Further in vivo studies to evaluate the adhesion/de-adhesion properties of the new hard-soft mesh material will be performed.

\section{Conclusions}

Here, we demonstrate an easy procedure to prepare smart and scalable mesh implants with modulated cell adhesion and cell de-adhesion properties. The bilayer system, composed of a $2 \mathrm{D}$-geometry and porous substrate (iPP mesh) and thermoresponsive hydrogel (PNIPAAm/MBA), is highly stable in dry and wet states. With a controlled hydrogel reaction time and crosslinker concentration, it was possible to obtain a new thermosensitive material with cell detachment (or antiadhesion) properties. The mechanism of cell adhesion and cell migration over time is strongly dependent on the morphology of the gel (porosity), the swelling ratio and the LCST temperature of the PNIPAAm-co-MBA composition. According to our results, a fixed amount of NIPAAm monomer $(250 \mathrm{mM})$ crosslinked with MBA ( $1 \mathrm{mM})$, for $2 \mathrm{~h}$ of grafting time, is the ideal condition to get one PP surface able to promote the de-adhesion of MCF-7 and COS-1 cells, for 7 days.

The novel material opens the door for evaluating the tissue integration (in vivo studies) of the new bilayer system, as a future outlook, pushing the frontiers of science in the development of new anti-adhesion prosthesis.

\section{Conflicts of interest}

There are no conflicts to declare.

\section{Acknowledgements}

This project has received funding from the European Union's Horizon 2020 research and innovation programme under the Marie Sklodowska-Curie grant agreement no. 796292 (Project 4DPOLYSENSE) and was also co-supported by MINECO (RTI2018098951-B-I00) and the Agència de Gestió d'Ajuts Universitaris i de Recerca (2017SGR359). Plasma equipment facilities and commercial mesh materials were supplied by B Braun Surgical S.A. (Spain), which partially co-funded this research. C. Alemán acknowledges the support received through the prize "ICREA Academia 2015" for excellence in research, funded by the Generalitat de Catalunya (Catalonia-Spain). 


\section{References}

1 V. Gómez-Gil, G. Pascual and J. Bellón, Processes, 2019, 7, 105.

2 U. Aydemir Sezer, V. Sanko, M. Gulmez, E. Sayman, B. Aru, Z. N. Yuksekdag, A. Aktekin, F. Vardar Aker and S. Sezer, ACS Biomater. Sci. Eng., 2017, 3, 3662-3674.

3 P. J. O’Dwyer, A. N. Kingsnorth, R. G. Molloy, P. K. Small, B. Lammers and G. Horeyseck, Br. J. Surg., 2005, 92, 166-170. 4 R. Bendavid, Hernia, 1997, 1, 5-8.

5 C. R. Costello, S. L. Bachman, B. J. Ramshaw and S. A. Grant, J. Biomed. Mater. Res., Part B, 2007, 83, 44-49.

6 Y. Yeo and D. S. Kohane, Eur. J. Pharm. Biopharm., 2008, 68, 57-66.

7 P. Avetta, R. Nisticò, M. G. Faga, D. D’Angelo, E. A. Boot, R. Lamberti, S. Martorana, P. Calza, D. Fabbri and G. Magnacca, J. Mater. Chem. B, 2014, 2, 5287-5294.

8 A. Huber, A. V. Boruch, A. Nieponice, H. Jiang, C. Medberry and S. F. Badylak, J. Biomed. Mater. Res., Part B, 2012, 100, 709-717.

9 W. Hu, Z. Zhang, S. Lu, T. Zhang, N. Zhou, P. Ren, F. Wang, Y. Yang and Z. Ji, Biomater. Sci., 2018, 6, 3030-3041.

10 U. Aydemir Sezer, V. Sanko, M. Gulmez, B. Aru, E. Sayman, A. Aktekin, F. Vardar Aker, G. Yanıkkaya Demirel and S. Sezer, Mater. Sci. Eng., C, 2019, 99, 1141-1152.

11 S. Lanzalaco, P. Turon, C. Weis, C. Alemán and E. Armelin, Soft Matter, 2019, 15, 3432-3442.

12 S. Lanzalaco and E. Armelin, Gels, 2017, 3, 36.

13 J. S. Moore, Q. Yu, B. Jo, R. H. Liu, C. Devadoss, D. J. Beebe and J. M. Bauer, Nature, 2002, 404, 588-590.

14 D. Seliktar, Science, 2012, 336, 1124-1128.

15 M. A. C. Stuart, W. T. S. Huck, J. Genzer, M. Müller, C. Ober, M. Stamm, G. B. Sukhorukov, I. Szleifer, V. V. Tsukruk, M. Urban, F. Winnik, S. Zauscher, I. Luzinov and S. Minko, Nat. Mater., 2010, 9, 101-113.

16 X. He, M. Aizenberg, O. Kuksenok, L. D. Zarzar, A. Shastri, A. C. Balazs and J. Aizenberg, Nature, 2012, 487, 214-218.

17 E. Kumacheva, Nat. Mater., 2012, 11, 665-666.

18 L. Liu, W. Wang, X. J. Ju, R. Xie and L. Y. Chu, Soft Matter, 2010, 6, 3759-3763.

19 K. Nagase, J. Kobayashi and T. Okano, J. R. Soc., Interface, 2009, 6, S293-S309.

20 A. Sidorenko, T. Krupenkin, A. Taylor, P. Fratzl and J. Aizenberg, Science, 2007, 315, 487-490.

21 Y. Takashima, S. Hatanaka, M. Otsubo, M. Nakahata, T. Kakuta, A. Hashidzume, H. Yamaguchi and A. Harada, Nat. Commun., 2012, 3, 1270-1278.

22 W. K. Wang, Z. Bin Sun, M. L. Zheng, X. Z. Dong, Z. S. Zhao and X. M. Duan, J. Phys. Chem. C, 2011, 115, 11275-11281.

23 J. Kim, J. A. Hanna, R. C. Hayward and C. D. Santangelo, Soft Matter, 2012, 8, 2375-2381.

24 J. Zhang, J. Wu, J. Sun and Q. Zhou, Soft Matter, 2012, 8, 5750-5752.

25 H. Banerjee, M. Suhail and H. Ren, Biomimetics, 2018, 3, 15.

26 X. Zhang, C. L. Pint, M. H. Lee, B. E. Schubert, A. Jamshidi, K. Takei, H. Ko, A. Gillies, R. Bardhan, J. J. Urban, M. Wu, R. Fearing and A. Javey, Nano Lett., 2011, 11, 3239-3244.

27 Y. Yamamoto, K. Kanao, T. Arie, S. Akita and K. Takei, ACS Appl. Mater. Interfaces, 2015, 4-8.
28 J. Kobayashi, A. Kikuchi, T. Aoyagi and T. Okano, J. Biomed. Mater. Res., Part A, 2019, 107, 955-967.

29 K. Nagase, T. Okano and H. Kanazawa, Nano-Struct. NanoObjects, 2018, 16, 9-23.

30 K. Nagase, M. Yamato, H. Kanazawa and T. Okano, Biomaterials, 2018, 153, 27-48.

31 N. Yamada, T. Okano, H. Sakai, F. Karikusa, Y. Sawasaki and Y. Sakurai, Makromol. Chem. Rapid. Commun., 1990, 11, 571-576.

32 Y. J. Kim and Y. T. Matsunaga, J. Mater. Chem. B, 2017, 5, 4307-4321.

33 M. D. Sarker, S. Naghieh, N. K. Sharma and X. Chen, J. Pharm. Anal., 2018, 8, 277-296.

34 S. Naghieh, E. Foroozmehr, M. Badrossamay and M. Kharaziha, Mater. Des., 2017, 133, 128-135.

35 M. Kharaziha, M. H. Fathi and H. Edris, Compos. Sci. Technol., 2013, 87, 182-188.

36 K. Iwai, Y. Matsumura, S. Uchiyama and A. P. de Silva, J. Mater. Chem., 2005, 15, 2796.

37 H. Liu and S. Wang, Sci. China: Chem., 2014, 57, 552-557.

38 P. Roach, D. J. McGarvey, M. R. Lees and C. Hoskins, Int. J. Mol. Sci., 2013, 14, 8585-8602.

39 B. R. Strohmeier, Surf. Interface Anal., 1990, 15, 51.

40 S. Hou, R. Lake, S. Park, S. Edwards, C. Jones and K. J. Jeong, ACS Appl. Bio Mater., 2018, 1, 1430-1439.

41 C. Yao, Z. Liu, C. Yang, W. Wang, X. Ju, R. Xie and L. Chu, Adv. Funct. Mater., 2015, 2980-2991.

42 C. L. Mark Chang, C.-Y. Lee, D. G. Castner, S. Sukavaneshvar, B. D. Ratner and T. A. Horbett, J. Biomed. Mater. Res., Part A, 2007, 828-837.

43 T. Takezawa, Y. Mori and K. Yoshizato, Nat. Biotechnol., 1990, 8, 854-856.

44 K. L. Prime and G. M. Whitesides, J. Am. Chem. Soc., 1993, 115, 10714-10721.

45 H. Liu, X. Zhang, S. Wang and L. Jiang, Small, 2015, 11, 3338-3342.

46 R. Ou, J. Wei, L. Jiang, G. P. Simon and H. Wang, Environ. Sci. Technol., 2016, 50, 906-914.

47 K. Zhu, D. Hou, Y. Fei, B. Peng, Z. Wang, W. Xu, B. Zhu, L.-L. Li and H. Wang, ACS Appl. Bio Mater., 2019, 2(8), 3582-3590.

48 P. Mostafalu, G. Kiaee, G. Giatsidis, A. Khalilpour, M. Nabavinia, M. R. Dokmeci, S. Sonkusale, D. P. Orgill, A. Tamayol and A. Khademhosseini, Adv. Funct. Mater., 2017, 27, 1-10.

49 C. Labay, J. M. Canal, M. Modic, U. Cvelbar, M. Quiles, M. Armengol, M. A. Arbos, F. J. Gil and C. Canal, Biomaterials, 2015, 71, 132-144.

50 U. Cvelbar, J. L. Walsh, M. Černák, H. W. de Vries, S. Reuter, T. Belmonte, C. Corbella, C. Miron, N. Hojnik, A. Jurov, H. Puliyalil, M. Gorjanc, S. Portal, R. Laurita, V. Colombo, J. Schäfer, A. Nikiforov, M. Modic, O. Kylian, M. Polak, C. Labay, J. M. Canal, C. Canal, M. Gherardi, K. Bazaka, P. Sonar, K. K. Ostrikov, D. Cameron, S. Thomas and K. D. Weltmann, Plasma Processes Polym., 2019, 16, 1-37.

51 T. Gan, Y. Guan and Y. Zhang, J. Mater. Chem., 2010, 20, 5937-5944. 